\title{
Analysis of the corrosion behavior of steel reinforcement protected by phosphate coatings
}

\author{
Viktoriya Konovalova* \\ Ivanovo State Polytechnic University, Department of natural sciences and technosphere safety, \\ Sheremetevsky av., 21, Ivanovo, 153000, Russia
}

\begin{abstract}
The influence of phosphate coatings on the corrosion behavior of steel reinforcement in a chloride-containing environment was studied to determine the need for additional protection against corrosion. The main indicators of the corrosion rate of steel reinforcement with phosphate coatings in chloride-containing solutions were determined, confirming the high protective properties of these coatings. It was found that the corrosion rate of steel reinforcement protected by phosphate coatings is reduced by 3 times. The processes of electrochemical corrosion of steel reinforcement of strength class A500S from steel grade St3ps in concrete under the influence of aggressive environments containing chloride ions $\left(2 \% \mathrm{MgCl}_{2}\right.$ solution and $\mathrm{HCl}$ solution with $\mathrm{pH}=5$ ) were studied. The kinetics of the corrosion process of steel reinforcement with and without protective phosphate coatings in solutions of various compositions has been studied. The change in mass of steel reinforcement protected by phosphate coatings is 3-4 times less than that of samples without coating. The surface potential of steel reinforcement with phosphate films changes significantly more slowly than that of unprotected samples.
\end{abstract}

\section{Introduction}

Reinforced concrete is widely known as a durable material that in most cases does not need any protection from the external environment. Steel reinforcement is usually protected by a layer of concrete. However, a lot of facts are known when there are both local damage and sometimes significant destruction of reinforced concrete structures, for example cracks in the concrete that cause the corrosion process [1-4].

One of the ways to inhibit the corrosion process is to apply a protective coating to the steel reinforcement, which would isolate it from the effects of aggressive substances [5-7]. Such coatings can be oxide, phosphate, zinc coatings or polymer films with good anticorrosion properties. Protective coatings for reinforcement are usually used in cases where other methods of ensuring its safety are not effective enough. The structure of anti-corrosion protection that was established at the end of the last decade is likely to continue for the foreseeable future (Fig. 1).

Chemical phosphating can be applied to carbon, low-and medium-alloy steels, cast iron, aluminum and magnesium alloys, zinc and cadmium coatings, etc. [8-14]. The essence of

\footnotetext{
* Corresponding author: kotprotiv@yandex.ru
} 
chemical phosphating consists in the treatment of metals and alloys in acidified solutions of single-substituted phosphates or monophosphates of iron, manganese, zinc, barium, calcium, etc.

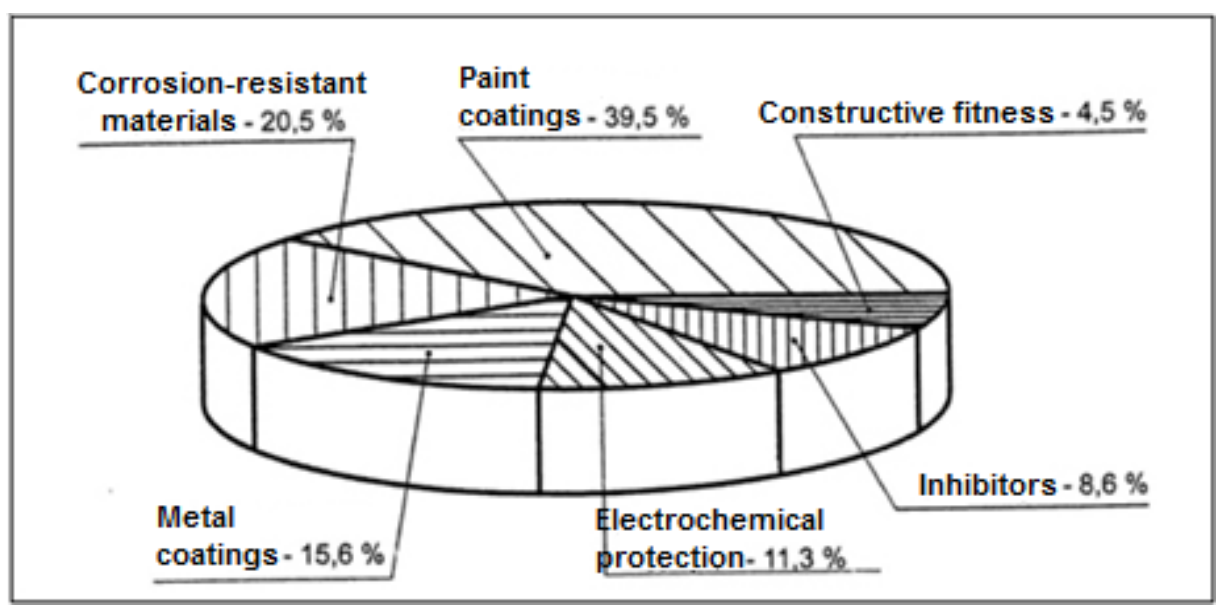

Fig. 1. Structure of expenses for anticorrosive protection of reinforced concrete reinforcement.

Coatings obtained from solutions of phosphates of several metals, such as primary iron and manganese phosphates or manganese and zinc, have the highest anticorrosive properties [15]. Films formed in a solution of manganese containing iron and zinc compounds have the best corrosion resistance [16]. When properly processed, the phosphate layer is a light gray 3-8 $\mu \mathrm{m}$ thick film with a fine crystalline structure and high adhesive and protective properties $[9,17]$.

It has been established that phosphate films provide mechanical protection of the metal surface against corrosion, therefore, it is necessary to obtain films with the lowest internal stresses to prevent cracking. This is achieved by introducing modifiers into the phosphating solution $[18,19]$.

The creation of a phosphate film on steel from cold phosphating solutions is promising for a number of reasons: the covered product does not require preparatory work (degreasing, etching, activation, etc.); solutions do not contain harmful and environmentally dangerous substances; maintaining the process at room temperature reduces energy consumption; steel hydrogenation is decreased; the processing time is reduced; sludge formation during phosphating is reduced; the formation of a film with a fine crystal structure is provided; coatings have a low porosity; phosphate films promote better chemical interaction between steel and concrete; the process of obtaining such films is cheap.

The study of the causes and the development of new methods for the prevention of corrosion damage reduces the cost of restoration and repair of products and structures and ensures the durability of their operation. Data on the rate of corrosion of metal surfaces make it possible to conclude that it is necessary to provide additional protection against corrosion when exposed to aggressive media. Despite the huge accumulated theoretical and practical material, the problems of corrosion at the interface between the phases of the metal and the composite coating remain unsolved.

\section{Materials and methods}

The studies were conducted on samples of steel reinforcement A500S made of steel grade St3ps. On the surface of the samples phosphate coatings were applied from cold phosphating solutions with the following composition: drug «Majef» 30-40 g/l; $\mathrm{Zn}\left(\mathrm{NO}_{3}\right)_{2} \quad 50-60 \mathrm{~g} / \mathrm{l}$; 
$\mathrm{NaNO}_{2}$ 3-4 g/l, with addition $1 \mathrm{~g} / 1$ of glucose or glycerin to accelerate deposition and improve coating quality, $6 \mathrm{~g} / \mathrm{l}$ of Trilon A or Trilon B as a buffer additive and $5 \mathrm{~g} / \mathrm{l}$ of emulsifiers OP-7, OP-10 or OS-20. Phosphating was carried out for 20 minutes at room temperature. After processing, samples of steel reinforcement were washed with running water and dried in air.

One of the main methods for studying the kinetics of electrode processes is the method of polarization curves, i.e. the study of the relationship between the current density $i$, reflecting the speed of the process, and the value of the potential of the electrode $E$. For a graphical method of calculating the speed and characteristics of the process, polarizing diagrams are built: $E_{\mathrm{a}}-i_{\mathrm{a}}$ is the curve of the anode polarization of the anode sections and $E_{\mathrm{\kappa}}$ $-i_{\mathrm{K}}$ is the the curve of cathode polarization of the cathode sections.

The model corrosion element (Fig. 2) was composed of a sample of A500S steel reinforcement made of St3ps steel and a graphite electrode, which were placed in different elbows of a U-shaped vessel. The working surface of the reinforcement sample was previously measured. The U-shaped vessel was filled with a $10 \% \mathrm{NaCl}$ solution. A saturated silver chloride electrode was used as the reference electrode.

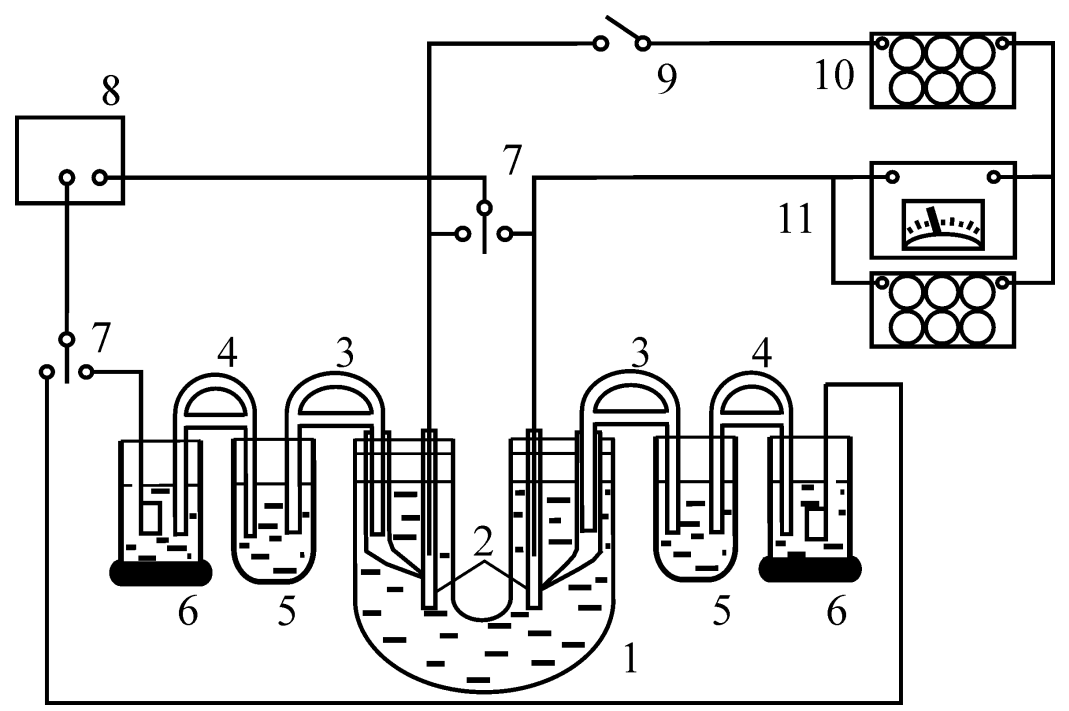

Fig. 2. Installation diagram for studying contact corrosion of metals: 1 - U-shaped vessel; 2 - test samples; 3 - electrolytic keys with the test solution; 4 - electrolytic keys with saturated $\mathrm{KCl}$ solution; 5 - intermediate glasses with the test solution; 6 - saturated silver chloride electrodes; 7 - switches; 8 - potentiometer; 9 - knife switch; 10 - resistance box; 11 - microammeter with a shunt resistance box.

Using a digital voltmeter, the potentials of the electrodes were measured, and their polarity was determined with an open circuit. Then the resistance at the decadal store was set: $50000,10000,5000,1000,500$ and $100 \mathrm{Ohm}$, and the potential values of the anode, cathode, and current were measured for each value of the external resistance.

The protective properties of coatings can be judged by two main indicators of corrosion: mass change indicator $\left(K_{m}^{-}, \mathrm{g} / \mathrm{m}^{2} \mathrm{~h}\right)$ and depth indicator $\left(K_{h}, \mathrm{~mm} / \mathrm{year}\right)$. These indicators were calculated using formulas (1) and (2) for the highest corrosion current determined from corrosion diagrams.

$$
K_{m}^{-}=\frac{I A}{z S \cdot 26,8}
$$




$$
K_{h}=K_{m}^{-} \frac{8,76}{\rho_{m e}}
$$

where: $I$ is a corrosion current, $\mathrm{A} ; A$ is a atomic mass of metal, $\Gamma ; z$ is a valency of a metal ion passing into solution; $S$ is a anode surface, $\mathrm{m}^{2} ; \rho_{m e}-$ metal density, $\mathrm{g} / \mathrm{sm}^{3}$.

\section{Results and discussion}

Test data on the corrosion protection of coatings by contact corrosion (Fig. 3) show that phosphate films with a finer crystalline structure more strongly inhibit the anodic dissolution of the protected metal. The depth corrosion index of modified phosphate coatings does not exceed $0,3 \mathrm{~mm} /$ year, and the allowable value ranges from 0,3 to $0,5 \mathrm{~mm} /$ year.

The kinetics of the corrosion process for 180 days of steel reinforcement with and without protective coatings in solutions of various compositions was studied. During this period, the value of the reinforcement potential and $\mathrm{pH}$ of the medium were determined.

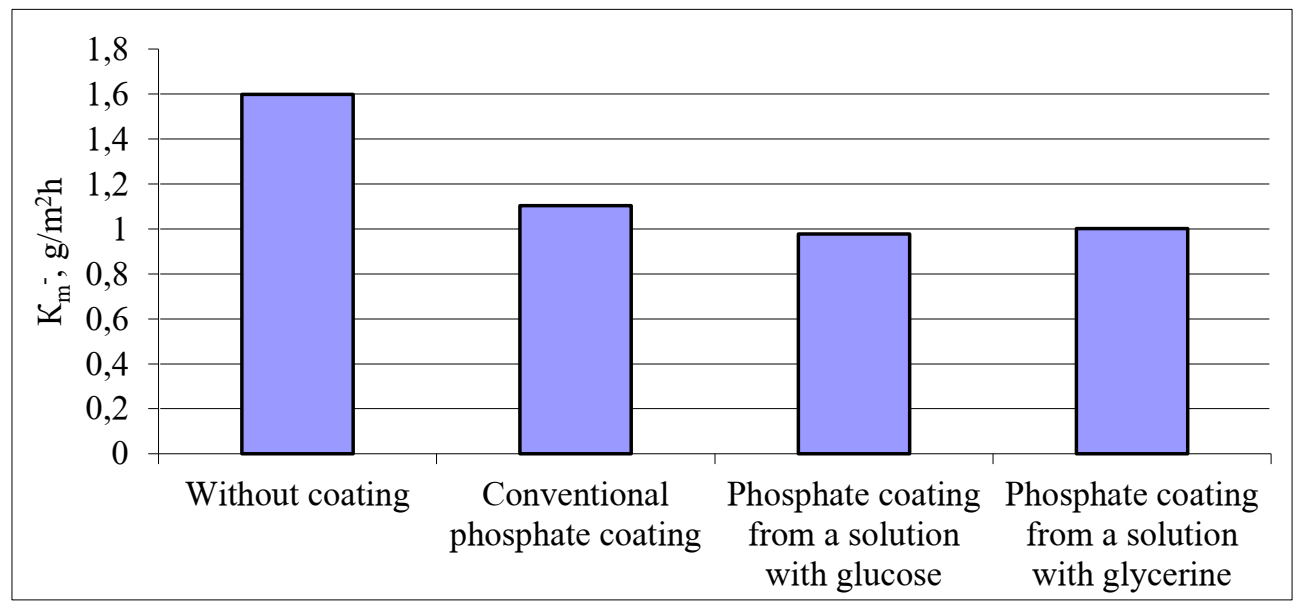

a)

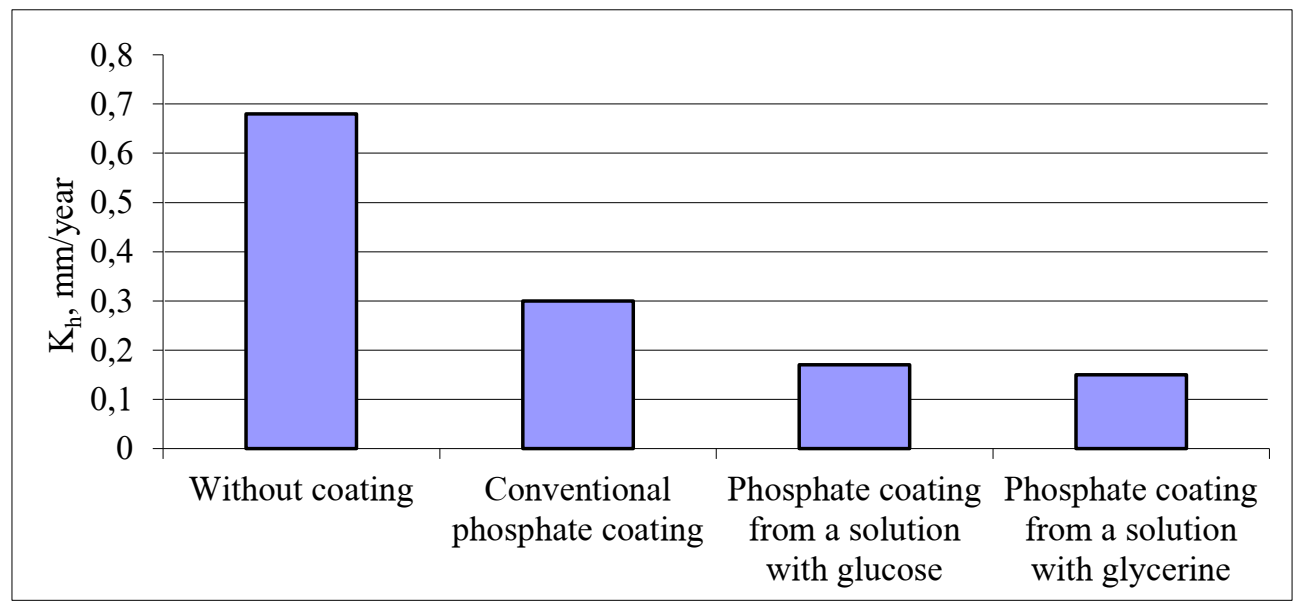

b)

Fig. 3. Corrosion rate indicators: a) mass change indicator; b) depth indicator. 
Table 1 shows that for samples protected by phosphate films, the potential change in the negative direction is not as sharp as for samples without protection. The potential value of the reinforcement protected by modified phosphate coatings was established constant 70 days after the start of the experiment, and for samples with a traditional phosphate coating it was established after 90 days. The value of the stationary potential of the reinforcement with protective coatings did not exceed $-400 \mathrm{mV}$ in all the studied solutions.

Table 1. Results of studies of the electrochemical state of reinforcement in various solutions

\begin{tabular}{|c|c|c|c|c|c|}
\hline \multirow{2}{*}{ Type of coating } & \multirow{2}{*}{ Solution } & \multicolumn{2}{|c|}{$\begin{array}{c}\text { Stationary potential } E_{s t}, \\
\mathrm{mV}\end{array}$} & \multicolumn{2}{|c|}{$\mathrm{pH}$} \\
\hline & & Initial state & $\begin{array}{l}\text { After } 6 \\
\text { months }\end{array}$ & $\begin{array}{c}\text { Initial } \\
\text { state }\end{array}$ & $\begin{array}{l}\text { After } 6 \\
\text { months }\end{array}$ \\
\hline \multirow{3}{*}{ Without coating } & Water & -315 & -440 & 6,3 & 6,45 \\
\hline & $2 \% \mathrm{MgCl}_{2}$ & -320 & -475 & 5,13 & 5,38 \\
\hline & $\mathrm{HCl}(\mathrm{pH}=5)$ & -320 & -488 & 5 & 5,21 \\
\hline \multirow{3}{*}{$\begin{array}{c}\text { Conventional phosphate } \\
\text { coating }\end{array}$} & Water & -310 & -389 & 6,3 & 6,37 \\
\hline & $2 \% \mathrm{MgCl}_{2}$ & -315 & -390 & 5,13 & 5,25 \\
\hline & $\mathrm{HCl}(\mathrm{pH}=5)$ & -320 & -396 & 5 & 5,11 \\
\hline \multirow{3}{*}{$\begin{array}{l}\text { Phosphate coating from a } \\
\text { solution with glucose }\end{array}$} & Water & -310 & -360 & 6,3 & 6,33 \\
\hline & $2 \% \mathrm{MgCl}_{2}$ & -315 & -355 & 5,13 & 5,18 \\
\hline & $\mathrm{HCl}(\mathrm{pH}=5)$ & -315 & -362 & 5 & 5,04 \\
\hline \multirow{3}{*}{$\begin{array}{l}\text { Phosphate coating from a } \\
\text { solution with glycerin }\end{array}$} & Water & -310 & -350 & 6,3 & 6,35 \\
\hline & $2 \% \mathrm{MgCl}_{2}$ & -310 & -360 & 5,13 & 5,15 \\
\hline & $\mathrm{HCl}(\mathrm{pH}=5)$ & -315 & -358 & 5 & 5,03 \\
\hline
\end{tabular}

In unprotected samples, the change in the electrode potential begins already on the 1415 th day of their being in a corrosive environment, and after 150 days the potential exceeds $-440 \mathrm{mV}$. Steel reinforcement protected by modified phosphate films keeps the potential at the level of $-320 \mathrm{mV}$ for 50 days. The protective properties of the coating are preserved. Further potential displacement in the negative direction is caused by the formation of the first corrosion centers under the influence of chloride ions penetrating to the steel surface. However, in samples protected by phosphate films, the potential change is not as sharp as in uncoated samples [20].

Mass losses of samples with modified coatings were $15-20 \mathrm{mg} / \mathrm{l}$, for reinforcement without protection this value reached $65 \mathrm{mg} / \mathrm{l}$. Phosphate films mechanically prevent the effect of a corrosive environment on steel. If the continuity of the protective coating is violated, local corrosion centers occur. Modifiers introduced into the composition of phosphating solutions improve the anticorrosive properties of coatings and reduce the likelihood of their cracking under the influence of internal stresses.

Table 2 shows the data obtained in the study of the anode behavior of reinforcement in concrete. Reinforcing bars were immersed in concrete mixture on Portland cement, and after curing the concrete in air for 28 days, the samples were placed in vessels with various solutions. After 6 months of testing there is a tendency to shift the potential to negative values. The $\mathrm{pH}$ values of the solutions are much lower than the value of 11,8 that required for passivation of steel reinforcement in concrete [21]. Changes in the $\mathrm{pH}$ of the medium to a decrease in acidity in all experiments are not significant.

The change in the potential of the reinforcement under the protection of the cement coating begins after six months of the samples being in a corrosive environment. The electrode potential gradually decreases, and after 18 months of testing, there is a tendency to establish a constant potential of reinforcement at the level of -270 to $-290 \mathrm{mV}$, which 
indicates the onset of equilibrium in the system "corrosive medium - concrete - steel reinforcement». The potential of reinforcement protected by phosphate films and located in concrete decreases only by $20-25 \mathrm{mV}$ during six months of testing due to the absence of aggressive particles to the steel surface.

Table 2. Results of studies of the electrochemical state of reinforcement in concrete

\begin{tabular}{|c|c|c|c|c|c|}
\hline \multirow{2}{*}{ Type of coating } & \multirow{2}{*}{ Solution } & \multicolumn{2}{|c|}{$\begin{array}{c}\text { Stationary potential } E_{s t}, \\
\mathrm{mV}\end{array}$} & \multicolumn{2}{|c|}{$\mathrm{pH}$} \\
\hline & & Initial state & $\begin{array}{l}\text { After } 6 \\
\text { months }\end{array}$ & $\begin{array}{c}\text { Initial } \\
\text { state }\end{array}$ & $\begin{array}{l}\text { After 6 } \\
\text { months }\end{array}$ \\
\hline \multirow{3}{*}{ Without coating } & Water & -210 & -270 & 6,3 & 6,35 \\
\hline & $2 \% \mathrm{MgCl}_{2}$ & -220 & -290 & 5,13 & 5,17 \\
\hline & $\mathrm{HCl}(\mathrm{pH}=5)$ & -220 & -295 & 5 & 5,04 \\
\hline \multirow{3}{*}{$\begin{array}{c}\text { Conventional phosphate } \\
\text { coating }\end{array}$} & Water & -165 & -205 & 6,3 & 6,33 \\
\hline & $2 \% \mathrm{MgCl}_{2}$ & -197 & -240 & 5,13 & 5,15 \\
\hline & $\mathrm{HCl}(\mathrm{pH}=5)$ & -200 & -240 & 5 & 5,03 \\
\hline \multirow{3}{*}{$\begin{array}{l}\text { Phosphate coating from a } \\
\text { solution with glucose }\end{array}$} & Water & -150 & -175 & 6,3 & 6,32 \\
\hline & $2 \% \mathrm{MgCl}_{2}$ & -155 & -175 & 5,13 & 5,15 \\
\hline & $\mathrm{HCl}(\mathrm{pH}=5)$ & -155 & -180 & 5 & 5,02 \\
\hline \multirow{3}{*}{$\begin{array}{l}\text { Phosphate coating from a } \\
\text { solution with glycerin }\end{array}$} & Water & -160 & -180 & 6,3 & 6,31 \\
\hline & $2 \% \mathrm{MgCl}_{2}$ & -165 & -180 & 5,13 & 5,14 \\
\hline & $\mathrm{HCl}(\mathrm{pH}=5)$ & -160 & -185 & 5 & 5,03 \\
\hline
\end{tabular}

The use of phosphate coatings as a protection for reinforcement is advisable in extremely aggressive environments or in cases where it is possible to crack concrete under excessive loads. In order to protect steel reinforcement from the occurrence of corrosion centers and its further spread over the entire surface, it is advisable to apply protective phosphate coatings on it, which do not interact well with the corrosive environment.

The mass loss of samples protected by phosphate coatings is insignificant and much lower than that of unprotected samples. Experimental data indicate high protective properties of modified phosphate coatings. Based on these results, phosphate films obtained from solutions containing modifiers can be recommended as coatings that meet the requirements for increased corrosion resistance.

\section{References}

1. F.U.A. Shaikh, Effect of Cracking on Corrosion of Steel in Concrete, International Journal of Concrete Structures and Materials, 12, p. 3 (2018)

2. O. Tope, F. Nigeria, A Contemporary Review of the Effects of Corrosion of Damaged Concrete Cover on the Structural Performance of Concrete Structure Using CFRP Strengthened Corroded Beam, Journal of Multidisciplinary Engineering Science and Technology (JMEST), vol. 1, 3, pp. 91-99 (2014)

3. V.P. Yartsev, A.N. Nikolyukin, T.M. Pluzhnikova, Assessment and Modeling of Bond Strength of Corroded Reinforcement in Concrete Structures, Advanced Materials and Technologies, 3, pp. 70-82 (2018)

4. V.A. Rybakov, K.G. Kozinetc, N.I. Vatin, V.Z. Velichkin, V.I. Korsun, Lightweight steel concrete structures technology with foam fiber-cement sheets, Magazine of Civil Engineering, vol. 82, 6, pp. 103-111 (2018) 
5. I. Sanri Karapinar, Effects of Coatings Containing Organic Ashes on the Corrosion Performance of Reinforcements, Advances in Civil Engineering, 2019, p. 8353678 (2019)

6. H. Binici, H. Zengin, G. Zengin, F. Yasarer, The use of pumice as a coating for the reinforcement of steel against corrosion and concrete abrasions, Corrosion Science, vol. 50, 8, pp. 2140-2148 (2008)

7. V. Kumar, Protection of steel reinforcement for concrete - A review, Corrosion Reviews, vol. 16, 4, pp. 317-358 (1998)

8. C. Jiang, X. Cheng, Anti-corrosion zinc phosphate coating on building steel via a facile one-step brushing method, Electrochemistry Communications, 109, p. 106596 (2019)

9. T.S.N.S. Narayanan, Surface pretreatment by phosphate conversion coatings - A review, Reviews on Advanced Materials Science, vol. 9, 2, pp. 130-177 (2005)

10. N. Van Phuong, K. Lee, D. Chang, M. Kim, S. Lee, S. Moon, Zinc phosphate conversion coatings on magnesium alloys: A review, Metal and Materials International, vol. 19, 2, pp. 273-281 (2013)

11. C. Jiang, Z. Gao, H. Pan, X. Cheng, The initiation and formation of a double-layer phosphate conversion coating on steel, Electrochemistry Communications, 114, p. 106676 (2020)

12. R. Li, Q. Yu, C. Yang, H. Chen, G. Xie, J. Guo, Innovative cleaner production for steel phosphorization using Zn-Mn phosphating solution, Journal of. Cleaner Production, vol. 18, 10, pp. 1040-1044 (2010)

13. V. Burokas, A. Martushene, A. Ruchinskene, A. Sudavichyus, G. Bikul'chyus, Deposition of amorphous phosphate coatings on aluminum, Protection of Metals, vol. 42, 4, pp. 339-344 (2006)

14. G. Bikulčius, O. Girčiene, A. Martušiene, E. Matulionis, The corrosion behaviour of electrochemical $\mathrm{Zn}$ coated with conversion chromate and phosphate films in concrete, Transactions of the Institute of Metal Finishing, vol. 80, 4, pp. 113-115 (2002)

15. D. Ivanov, Phosphating of Carbon Steels in Solutions Containing Zinc and ZincManganese Phosphates, IOP Conference Series: Materials Science and Engineering, 374, p. 012033 (2018)

16. J.F. Andrew, S.G. Clarke, E.E. Longhurst, The protective properties of various phosphate coatings on steel, Journal of Applied Chemistry, vol. 4, 11, pp. 581-595 (2007)

17. C.H.S.B. Teixeira, E.A. Alvarenga, W.L. Vasconcelos, V.F.C. Lins, Effect of porosity of phosphate coating on corrosion resistance of galvanized and phosphated steels Part II: Evaluation of corrosion resistance, Materials and Corrosion, vol. 62, 9, pp. 853-860 (2011)

18. B. Ptacek, F. Dalard, J.J. Rameau, Iron phosphating in a trichloroethylene solution, Surface and Coatings Technology, 82, pp. 277-283 (1996)

19. O.I. Kropacheva, T.S. Devyatkina, N.A. Skornyakova, S.I. Saunina, Deposition and Properties of Phosphate Coatings on Galvanized Steel, Protection of Metals, 39, pp. 325-328 (2003)

20. S. Fedosov, V. Roumyantseva, V. Konovalova, Phosphate coatings as a way to protect steel reinforcement from corrosion, MATEC Web Conferences, 298, p. 00126 (2019)

21. Q. Pu, Y. Yao, L. Wang, X. Shi, J. Luo, Y. Xie, The investigation of $p H$ threshold value on the corrosion of steel reinforcement in concrete, Computers and Concrete, vol. 19, 3, pp. 257-262 (2017) 